\title{
Analisis Sebaran Klorofil-A dan Suhu Permukaan Laut sebagai Fishing Ground Potensial (Ikan Pelagis Kecil) di Perairan Kendal, Jawa Tengah
}

\section{Andita Agung N..$^{1 *}$, Muhammad Zainuri, ${ }^{1,2}$ dan Anindya Wirasatriya ${ }^{1,2}$, Lilik Maslukah ${ }^{1,2}$, Petrus Subardjo ${ }^{1}$, Agus Anugroho Dwi Suryosaputro ${ }^{1}$, Gentur Handoyo ${ }^{1}$}

\author{
${ }^{I}$ Departemen Oseanografi, Fakultas Perikanan dan Ilmu Kelautan, Universitas Diponegoro \\ Jl. Prof. Soedarto, SH, Tembalang, Semarang, Jawa Tengah, 50275 \\ ${ }^{2}$ Pusat Kajian Mitigasi Bencana dan Rehabilitasi Pesisir, Universitas Diponegoro \\ Jl. Prof. Soedarto, SH, Tembalang, Semarang, Jawa Tengah, 50275 \\ Email : anditaagung17@gmail.com
}

\begin{abstract}
Abstrak
Perairan Kendal merupakan salah satu kabupaten di Jawa Tengah dengan luas wilayah $\pm 1.002,23$ $\mathrm{km}^{2}$ dan mengalami perkembangan pesat terutama di bidang perikanan. Perairan Kendal adalah salah satu wilayah penyebaran ikan demersal dan pelagis yang cukup potensial di perairan Utara Jawa Tengah. Tujuan penelitian ini untuk memprediksi zonasi fishing ground ikan pelagis kecil di Perairan Kendal berdasarkan parameter klorofil-a dan suhu permukaan laut. Penelitian ini menggunakan metode kuantitatif, penentuan lokasi pengambilan sampel menggunakan metode purposive sampling. Berdasarkan hasil penelitian diketahui bahwa perairan Kendal memiliki nilai konsentrasi klorofil-a berkisar antara $0.34-4.86 \mathrm{mg} / \mathrm{m}^{3}$ konsentrasi tertinggi di Timur Laut muara sungai Bodri dan di ikuti dengan hasil tangkapan ikan paling banyak yaitu $53 \mathrm{~kg}$. Konsentrasi suhu permukaan laut berkisar $30,5-31^{\circ} \mathrm{C}$. Perbedaan nilai konsentrasi klorofil-a dan suhu permukaan laut dipengaruhi oleh angin yang berhembus di perairan sehingga diduga mengakibatkan terjadinya proses mixing.
\end{abstract}

Kata kunci: fishing ground, Ikan pelagis kecil, Citra Aqua MODIS

\section{Abstract \\ Analysis of Chlorophyll-A Distribution and Potential Sea Surface As Fishing Ground Temperature in Kendal Coastal, Central Java}

The waters of Kendal is one district in Central Java with an area of $\pm 1.002 .23 \mathrm{~km}^{2}$ and experienced rapid development, especially in the field of fisheries. The waters of Kendal is one of the potential demersal and pelagic fish distribution areas in the waters of North Central Java. The purpose of this study was to predict the potential fishing ground of small pelagic fish in Kendal Waters based on the parameters of chlorophyll-a and sea surface temperature. This research uses quantitative method while determining the location of sampling using purposive sampling method. Based on the research results it can be seen that the waters of Kendal has a value of chlorophyll-a concentration ranging from $0.34-4.86$ $\mathrm{mg} / \mathrm{m}^{3}$ with the highest concentration that is in the Northeast estuary Bodri river and followed by the catch of most fish that is $53 \mathrm{~kg}$. Concentrations of sea surface temperature range from $30.5-31^{\circ} \mathrm{C}$. Differences in the value of a-chlorophyll concentration and sea-surface temperatures across the waters are influenced by winds that blow in the waters resulting in a mixing process.

Keywords: fishing ground, small pelagis fish, Aqua MODIS Imagery.

\section{PENDAHULUAN}

Perairan Kendal merupakan salah satu kabupaten di Jawa Tengah dengan luas wilayah \pm $1.002,23 \mathrm{~km}^{2}$ dan mengalami perkembangan pesat terutama di bidang perikanan. Perairan
Kendal adalah salah satu wilayah penyebaran ikan demersal dan pelagis yang cukup potensial di perairan Utara Jawa Tengah. Usaha untuk meningkatkan pemanfaatan sumberdaya perikanan dalam bidang penangkapan, dan 
nampak sekali telah terjadi fluktuasi jumlah hasil tangkapan tiap tahun khususnya ikan pelagis di daerah Kendal (Rahman et al., 2013).

Klorofil-a adalah suatu pigmen hijau yang dapat ditemukan pada algae, tumbuhan, dan cyanobacteria. Klorofil-a merupakan suatu pigmen aktif dalam sel tumbuhan yang mempunyai peranan penting dalam terjadinya proses fotosintesis di perairan yang dapat digunakan sebagai indikator jumlah ikan yang ada di wilayah tersebut. Parameter yang menjadi penentu pada perairan yang terdapat banyak ikannya yaitu salah satunya parameter suhu permukaan laut. Ikan pelagis mempunyai habitat hidup di wilayah perairan pesisir laut dan pada umumnya berenang berkelompok dalam jumlah yang sangat besar. Tujuan pembentukan kelompok dalam jumlah besar adalah sebagai upaya memudahkan mencari makan, mencari pasangan dalam memijah dan taktik untuk menghindar atau mempertahankan diri dari serangan predator (Pavlov dan Kasumyan, 2000).

Wind mixing adalah proses tercampurnya massa air laut karena pengaruh angin (Marshal dan Plumb, 2008). Silubun et al. (2015) menyatakan bahwa terjadinya mixing menyebabkan nilai suhu permukaan laut (SPL) rendah, salinitas tinggi, densitas tinggi, oksigen relatif rendah dan nutrien tinggi yang dapat menyebabkan fitoplankton melimpah.

Masyarakat wilayah pesisir Kabupaten Kendal mayoritas memiliki mata pencaharian sebagai nelayan dan untuk kehidupan sehari hari sangat menggantungkan dari hasil tangkapan ikan di perairan Kendal. Kegiatan penangkapan ikan di perairan Kendal sangat berkembang begitu pesat dan sangat padat. (Rahman et al., 2013) menyatakan bahwa penelitian analisis potensi dan permasalahan sumberdaya ikan pelagis kecil di perairan Utara Jawa Tengah dengan menggunakan model surplus produksi schaefer. Proses penangkapan ikan yang berlebihan akan mempengaruhi habitat ikan di perairan Kendal. Tujuan penelitian ini adalah untuk memprediksi zonasi fishing ground ikan pelagis kecil di Perairan Kendal berdasarkan parameter klorofil-a dan suhu permukaan laut.

\section{MATERI DAN METODE}

Data primer yang digunakan yaitu meliputi data Klorofil-a, data Suhu permukaan laut, data Tangkapan ikan di laut dan dari Pelabuhan Perikanan Pantai Tawang Jawa Tengah. Data sekunder digunakan sebagai pendukung dari data primer, yaitu meliputi Citra Aqua MODIS Klorofil-a harian Level 2 dengan resolusi spasial 1 $\mathrm{km} \times 1 \mathrm{~km}$ referensi NASA, ftp.nasa.jpl bla3 dan data Angin dari ECMWF (European Centre for Medium-Range Weather Forecasts).

Metode penelitian yang digunakan adalah metode kuantitatif, yaitu metode penelitian menggunakan data berupa angka dari pengumpulan data dan hasilnya yang berupa gambar, tabel, grafik, atau tampilan lainnya,

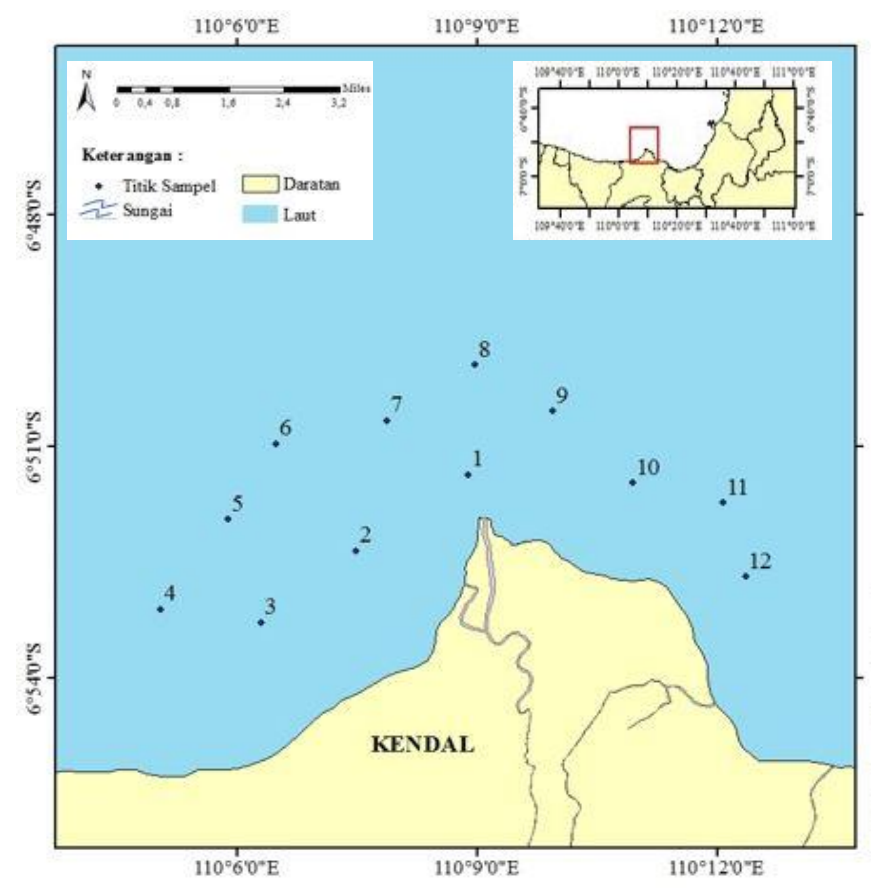

Gambar 1. Peta Lokasi Penelitian 
bersifat sistematis dan analisisnya menggunakan statistik (Sugiyono, 2015). Penentuan titik sampling menggunakan metode purposive sampling (Arikunto, 2010).

Pengambilan sampel klorofil-a yaitu mengambil samper air laut sebanyak 1 liter menggunakan botol Nansen, sampel air dimasukkan kedalam botol yang tidak tembus cahaya matahari dan disimpan dalam coolbox yang dingin. Pengambilan dilakukan pada 12 stasiun pengamatan dengan kedalaman kurang lebih 1 meter, kemudian di lakukan pengecekan suhu permukaan laut menggunakan alat Water Quality Meter (WQC). Data tangkapan ikan diperoleh dari nelayan pada saat menangkap ikan di laut dengan diperkuat dari data Pelabuhan Perikanan Pantai Tawang Kendal.

Penentuan lokasi titik pengambilan sampel dilakukan dengan menggunakan Global Positioning System (GPS) yang lokasinya sudah ditentukan sebelumnya. Pengambilan data di lokasi penelitian dilakukan pada tanggal 24 Oktober 2017 di perairan Kendal Jawa Tengah dengan jumlah titik yang diambil sebanyak 12 titik lokasi stasiun.

Analisis sampel klorofil-a yaitu menggunakan metode analisis menurut (Eaton et al, 1999) yaitu : Air sampel sebanyak 1 Liter disaring menggunakan Nitrocellulose Membrane dengan tipe $0.45 \mathrm{vm}$ HA dengan bantuan vakum pump. Kemudian diberikan $\mathrm{MgCO}_{3}+$ aquabides, yang bertujuan untuk mencegah kerusakan klorofil-a atau menjaga suhu pada saat proses penyaringan. Kertas saring yang mengandung klorofil-a dilipat empat kali sampai menjadi lipatan kecil. Kemudian dimasukkan kedalam alumunium foil. Lipatan sampel klorofil-a kemudian disimpan dalam kulkas dengan suhu $4^{\circ} \mathrm{C}$ sampai prosedur berikutnya. Kemudian ditambahkan $15 \mathrm{ml}$ aseton $90 \%$ untuk melarutkan kertas saring sampai dengan hancur merata. Sampel dipindahkan kedalam tabung reaksi dan disimpan dalam kulkas dengan suhu $4^{\circ} \mathrm{C}$ selama 1 jam. Sampel yang di ekstrak dimasukkan kedalam mesin sentrifuge dan tambahkan 2 sampai $3 \mathrm{ml}$ aseton $90 \%$ kemudian diputar dengan kecepatan 500 rpm dengan waktu selama 1 sampai 15 menit. Kemudian sampel dipindah ke cuvette dengan ukuran $1 \mathrm{~cm}$. Sampel dianalisis menggunakan spektrofotometri UV-Vis dengan panjang gelombang $750 \mathrm{~nm}, 664 \mathrm{~nm}, 647 \mathrm{~nm}$ dan $630 \mathrm{~nm}$.

Panjang gelombang $750 \mathrm{~nm}$ adalah koreksi untuk kekeruhan. Sebelum menghitung dengan persamaan rumus (Pers.1) maka masing masing nilai panjang gelombang $664 \mathrm{~nm}, 647 \mathrm{~nm}$ dan 630 $\mathrm{nm}$ dikurangi dengan nilai panjang gelombang $750 \mathrm{~nm}$. Konsentrasi klorofil-a dihitung dengan persamaan sebagai berikut :

$$
\begin{array}{cc}
C a=11.85(\text { OD664) } & -1.54(\text { OD647) } \\
\text { 0.08(OD630) } & \text { (Pers.1) }
\end{array}
$$

Keterangan :

$\mathrm{Ca}=$ kadar klorofil-a $\left(\mathrm{mg} / \mathrm{m}^{3}\right)$

$11.85,1.54,0.08=$ Nilai tetapan

(OD664), $($ OD647),$($ OD630 $)=$ Nilai pengukuran spektrofotometer

Setelah menentukan konsentrasi yang sudah di ekstrak, kemudian dihitung jumlahnya per satuan volume, sebagai berikut :

$$
\text { Chlorophyll } a, \frac{m g}{m^{3}}=\frac{C_{a} \times \text { Extract volume, } m g}{\text { volume of sample, } m^{3}}
$$

Keterangan :

$\mathrm{Ca}=$ konsentrasi yang di hitung dari

Extract volume $=$ volume yang di ekstract $(\mathrm{mg})$

Volume sampel $=$ volume sampel digunakan $(\mathrm{L})$

\section{Analisis Data Citra Aqua MODIS Klorofil-a dan Suhu permukaan laut}

Data citra klorofil-a dan suhu permukaan laut dapat di download melalui https://oceancolor. gsfc.nasa.gov/ berupa data harian Level 2 resolusi $\begin{array}{llllllll}\text { spasial } & 1 & \mathrm{~km} & \mathrm{x} & 1 & \mathrm{~km} & \text { Proses selanjutnya }\end{array}$ merupakan proses pengolahan data Klorofil-a dengan menggunakan software Seadas. Data selama 3 tahun akan di komposit menjadi data bulanan, kemudian akan di buat dalam bentuk peta sebaran klorofil-a dan suhu permukaan laut menggunakan software ArcGIS yang dapat di jadikan acuan untuk prakiraan zonasi fishing ground potensial ikan pelagis kecil.

\section{Analisis Data Angin}

Data arah dan kecepatan angin diperoleh dengan observasi tidak langsung, yaitu menggunakan data dari website http://www. ecmwf.int/. Data angin yang digunakan adalah data angin per jam selama 3 tahun. Data tersebut diolah menggunakan software Ocean Data View (ODV) dan Microsoft Excel kemudian ditampilkan menggunakan software ArcGIS. Data tersebut cukup representatif untuk melihat pergerakan arus untuk memprediksi persebaran klorofil-a dan suhu permukaan laut di perairan Kendal. 


\section{HASIL DAN PEMBAHASAN}

\section{Peta Hasil Tangkapan Ikan Dihubungkan dengan Klorofil-a insitu}

Berdasarkan peta pada Gambar 2, nilai konsentrasi klorofil terendah di stasiun 4 yaitu 0,3 $\mathrm{mg} / \mathrm{m}^{3}$ dengan hasil tangkapan ikan $14 \mathrm{~kg}$ dan konsentrasi klorofil-a tertinggi pada stasiun 9 yaitu $4,8 \mathrm{mg} / \mathrm{m}^{3}$ dengan hasil tangkapan ikan 53 kg. Nilai konsentrasi klorofil-a dominan tinggi yaitu berada di depan Muara Sungai Bodri dan menjorok ke laut lepas. Semakin bertambah nilai konsentrasi klorofil-a maka akan di ikuti dengan semakin bertambahnya jumlah hasil tangkapan ikan di perairan tersebut. Konsentrasi klorofil-a terendah disimbolkan dengan warna biru, tertinggi disimbolkan dengan warna merah dan mempunyai bentuk lingkaran paling besar. Semakin tinggi nilai konsentrasi klorofil-a memiliki hasil tangkapan ikan semakin banyak. Berdasarkan grafik pada Gambar 3, memiliki nilai $R^{2}=0.7685$ dimana dapat disimpulkan bahwa nilai regresi menunjukkan $76 \%$ tangkapan ikan telah dipengaruhi oleh faktor konsentrasi klorofil-a di perairan tersebut. Kedua parameter mempunyai hubungan keeratan yang kuat dengan ditandai nilai $\mathrm{R}=0.877$.

\section{Peta Hasil Tangkapan Ikan Dihubungkan dengan Suhu Permukaan Laut (SPL) insitu}

Peta hasil tangkapan ikan dihubungkan dengan konsentrasi suhu permukaan laut di perairan Kendal Jawa Tengah dapat ditunjukkan pada Gambar 4. Nilai suhu permukaan laut paling rendah pada stasiun 11 dan 12 yaitu $30,5{ }^{\circ} \mathrm{C}$ dengan tangkapan ikan $32-39 \mathrm{~kg}$ dan Nilai suhu permukaan laut paling tinggi pada stasiun 1 yaitu $31^{\circ} \mathrm{C}$ dengan tangkapan ikan $46 \mathrm{~kg}$. Nilai suhu permukaan laut di sebelah timur Muara Sungai Bodri relatif rendah dan di sebelah barat dominan tinggi. Berdasarkan Gambar 4, nilai suhu permukaan laut terendah ditandai dengan

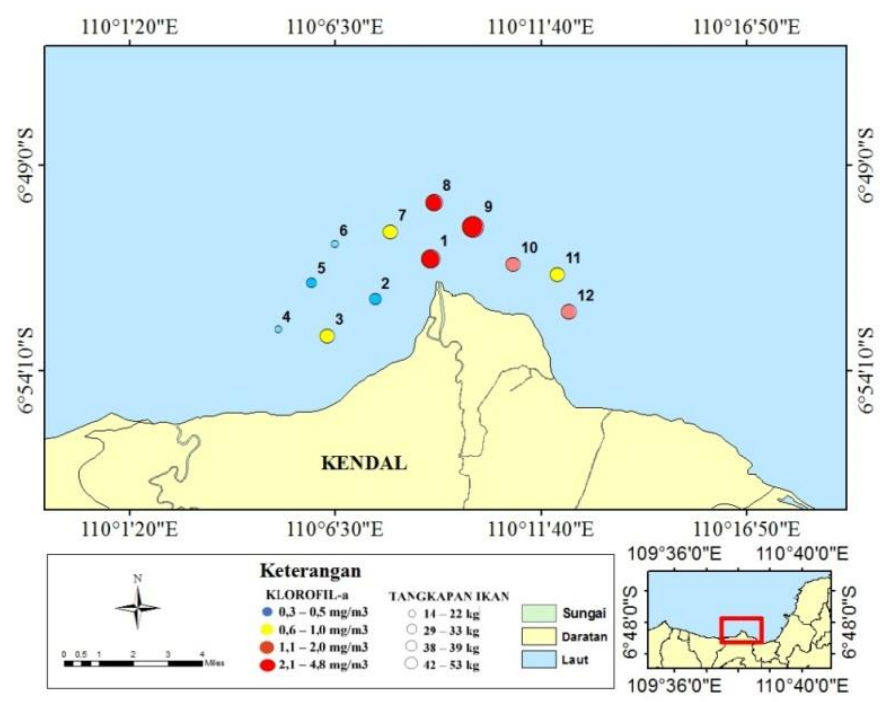

Gambar 2. Hubungan Antara Hasil Tangkapan Ikan Pelagis Kecil Dengan Klorofil-a insitu di Perairan Kendal Secara Spasial.

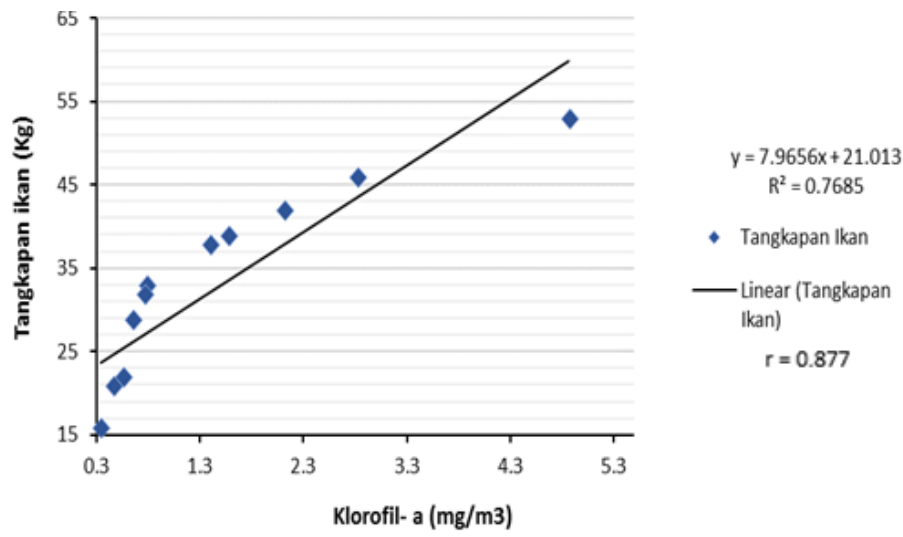

Gambar 3. Grafik Scatter Plot Tangkapan Ikan vs Klorofil-a. 
warna kuning dan tertinggi dengan warna merah. Besarnya lingkaran menunjukkan hasil tangkapan ikan. Setiap bertambahnya nilai suhu permukaan laut tidak di ikuti dengan semakin banyaknya hasil tangkapan ikan. Berdasarkan grafik pada Gambar 5, memiliki nilai $R^{2}=0.0028$ dimana dapat disimpulkan bahwa berdasarkan grafik regresi pengaruh nilai suhu permukaan laut terhadap hasil tangkapan ikan sangat kecil. Kedua parameter mempunyai hubungan keeratan yang sangat lemah dengan ditandai nilai $\mathrm{R}=0.053$, dengan demikian parameter SPL tidak dikaji lebih lanjut untuk menentukan fishing ground.

\section{Pengaruh Angin Terhadap Klorofil-a di Wilayah Pesisir dan Lepas Pantai}

Berdasarkan hasil pengolahan data scatter angin menunjukkan besarnya hembusan angin di perairan pesisir hingga lepas pantai sekitar 1,6 $3,7 \mathrm{~m} / \mathrm{s}$. Pengaruh angin terhadap persebaran klorofil-a di wilayah pesisir pengaruhnya sangat kecil dimana dibuktikan dengan nilai $R^{2}=-0,026$ dan pengaruh angin terhadap persebaran klorofila di wilayah lepas pantai sangat besar dibuktikan dengan nilai $R^{2}=0,616$, (Gambar 6 dan 7)

\section{Keterkaitan Klorofil-a, Angin dan Fishing Ground}

Studi-studi terdahulu yang dilakukan di lepas pantai telah menunjukkan bahwa kandungan klorofil-a (SPL) yang tinggi (rendah) memiliki korelasi yang kuat dengan tingginya hasil tangkapan ikan (Kunarso et al., 2018; Sachoemar et al., 2010; Sachoemar et al., 2012). Tingginya konsentrasi klorofil-a menunjukkan tingginya kelimpahan fitoplankton yang juga menunjukkan tingginya populasi zooplankton sehingga menarik sekumpulan ikan untuk datang. Sedangkan kuatnya korelasi negatif antara SPL dan klorofil-a dapat dijelaskan mekanismenya melalui parameter angin (Setiawan dan Habibi, 2011; Wirasatriya et al., 2017; Wirasatriya et al., 2018ab). Semakin cepat angin bertiup maka proses mixing dalam kolom akan semakin kuat. Proses mixing ini akan mengangkat massa air dingin yang kaya akan nutrient dari kolom perairan yang lebih dalam sehingga menyebabkan meningkatnya kandungan klorofil-a di lapisan permukaan dan menurunnya SPL. Semakin cepat angin bertiup menyebabkan perpindahan panas laten dari permukaan laut ke udara sehingga menurunkan SPL. Namun demikian analisis data insitu dalam penelitian ini kami menemukan bahwa hasil tangkapan ikan di pesisir perairan utara Kendal lebih dipengaruhi oleh klorofil-a dari pada SPL. Penentuan fishing ground menggunakan data satelit, kami hanya menggunakan parameter klorofil.

Hasil pengolahan data citra Aqua MODIS klorofil-a klimatologi tumpang tindih dengan data angin pada bulan Januari - Desember selama 3 tahun. Nilai konsentrasi klorofil-a yaitu berkisar antara $0,1-24 \mathrm{mg} / \mathrm{m}^{3}$ dengan tiga kategori rendah, sedang dan tinggi, disajikan pada Gambar 8. Penentuan tiga kategori tersebut dihubungkan dengan lokasi fishing ground di perairan Kendal berdasarkan jumlah pixel dari data pengolahan citra sesuai dengan kategori yang telah ditentukan, disajikan pada Tabel 1. Daerah dengan klorofil-a tinggi (> $4.4 \mathrm{mg} / \mathrm{m}^{3}$ ) yang menunjukkan tingginya potensi fishing ground tersebar hampir di sepanjang pesisir utara Kendal di setiap bulannya. Maka dari hasil analisa tersebut penangkapan ikan pelagis di Kab. Kendal sebaiknya dilakukan di dekat pantai.

Tabel 1. Jumlah Lokasi potensi Fishing ground di perairan Kendal

\begin{tabular}{cccccc}
\hline \multirow{2}{*}{ No } & \multirow{2}{*}{ Bulan } & Jumlah lokasi potensi fishing & \multicolumn{3}{c}{ Kategori } \\
\cline { 3 - 5 } & & ground & Rendah & Sedang & Tinggi \\
\hline 1 & Januari & 16 & - & 11 & 5 \\
2 & Februari & 11 & - & 7 & 4 \\
3 & Maret & 16 & - & 9 & 7 \\
4 & April & 13 & - & 7 & 6 \\
5 & Mei & 11 & - & 7 & 4 \\
6 & Juni & 13 & - & 8 & 5 \\
7 & Juli & 9 & - & 4 & 5 \\
8 & Agustus & 11 & - & 7 & 5 \\
9 & September & 14 & - & 3 & 7 \\
10 & Oktober & 11 & - & 6 & 5 \\
11 & November & 11 & - & 8 & 6 \\
12 & Desember & 14 & &
\end{tabular}




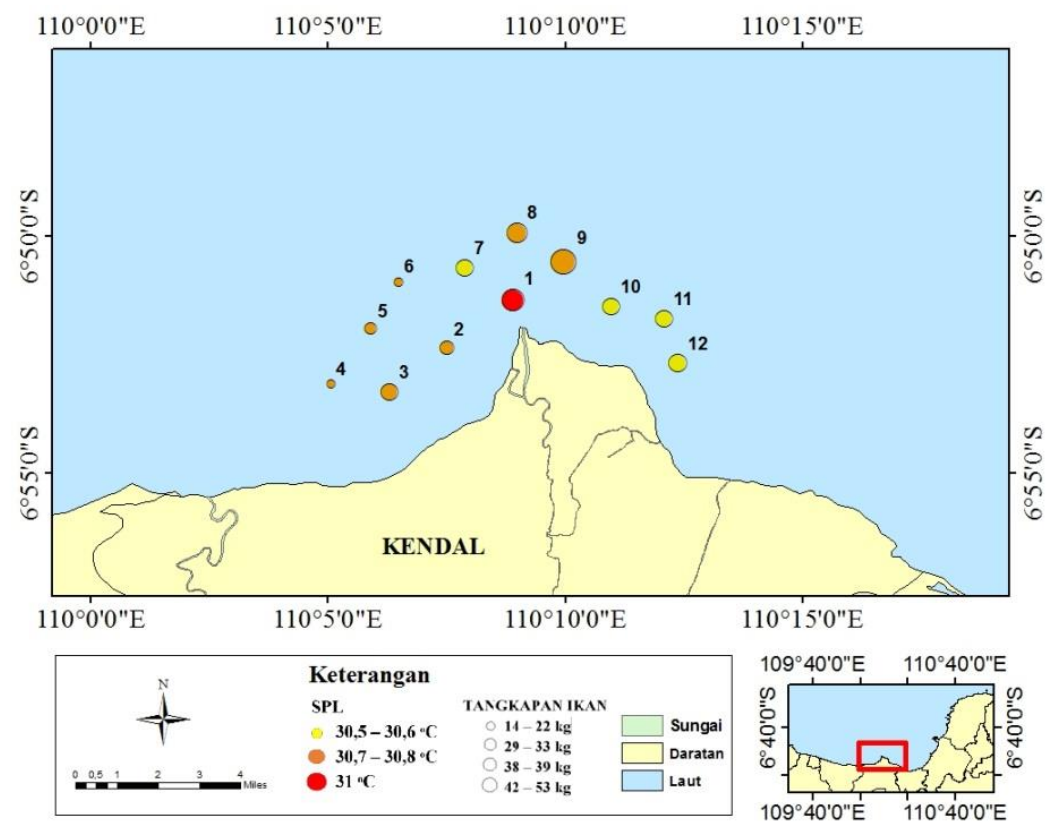

Gambar 4. Hubungan Antara Hasil Tangkapan Ikan Pelagis Kecil dengan Suhu Permukaan Laut insitu di Perairan Kendal Secara Spasial.

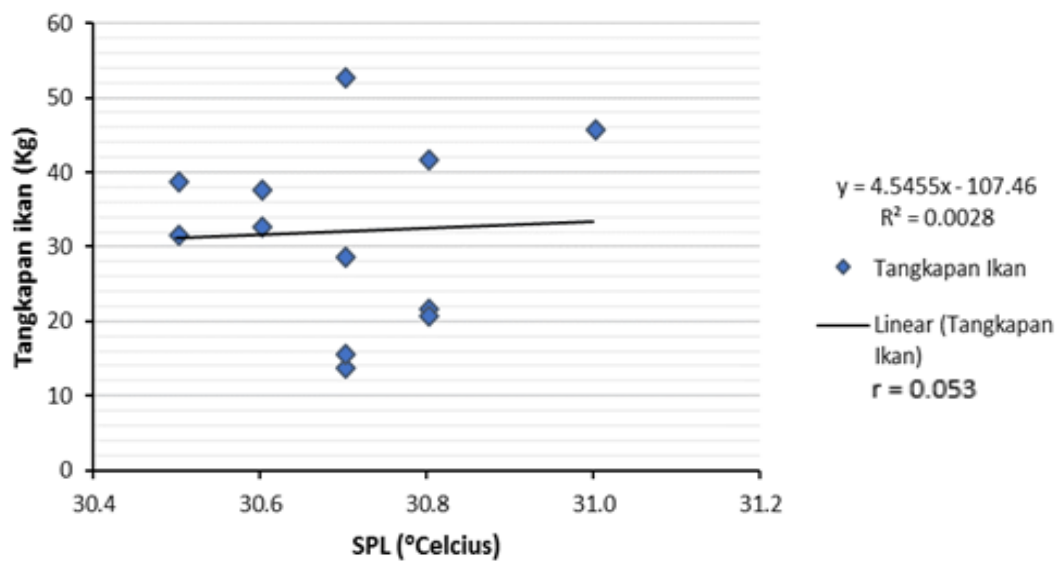

Gambar 5. Grafik Scatter Plot Tangkapan Ikan vs SPL.

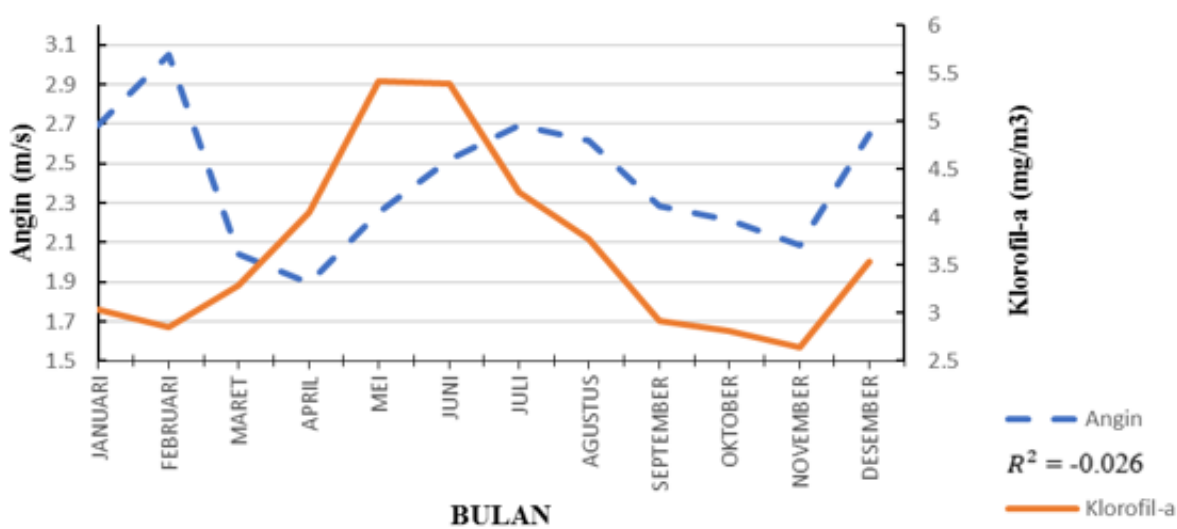

Gambar 6. Pengaruh Angin Terhadap Klorofil-a di Wilayah Pesisir. 


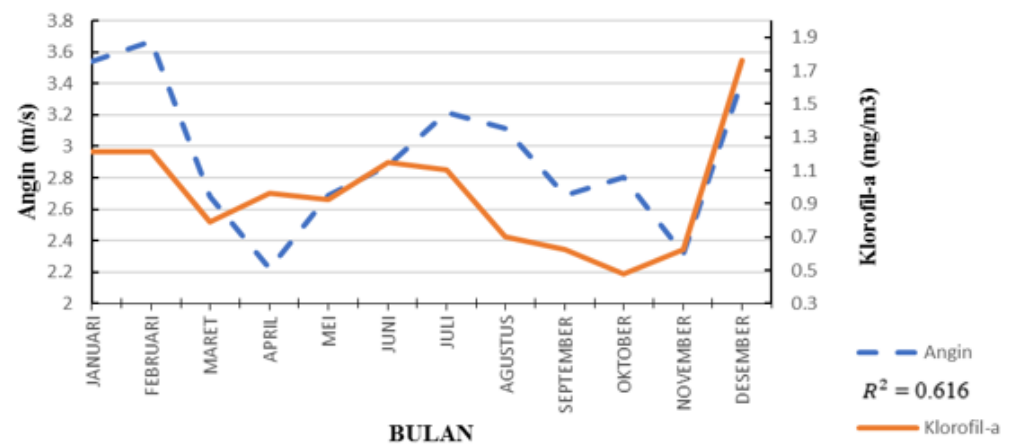

Gambar 7. Pengaruh Angin Terhadap Klorofil-a di Wilayah Lepas Pantai.
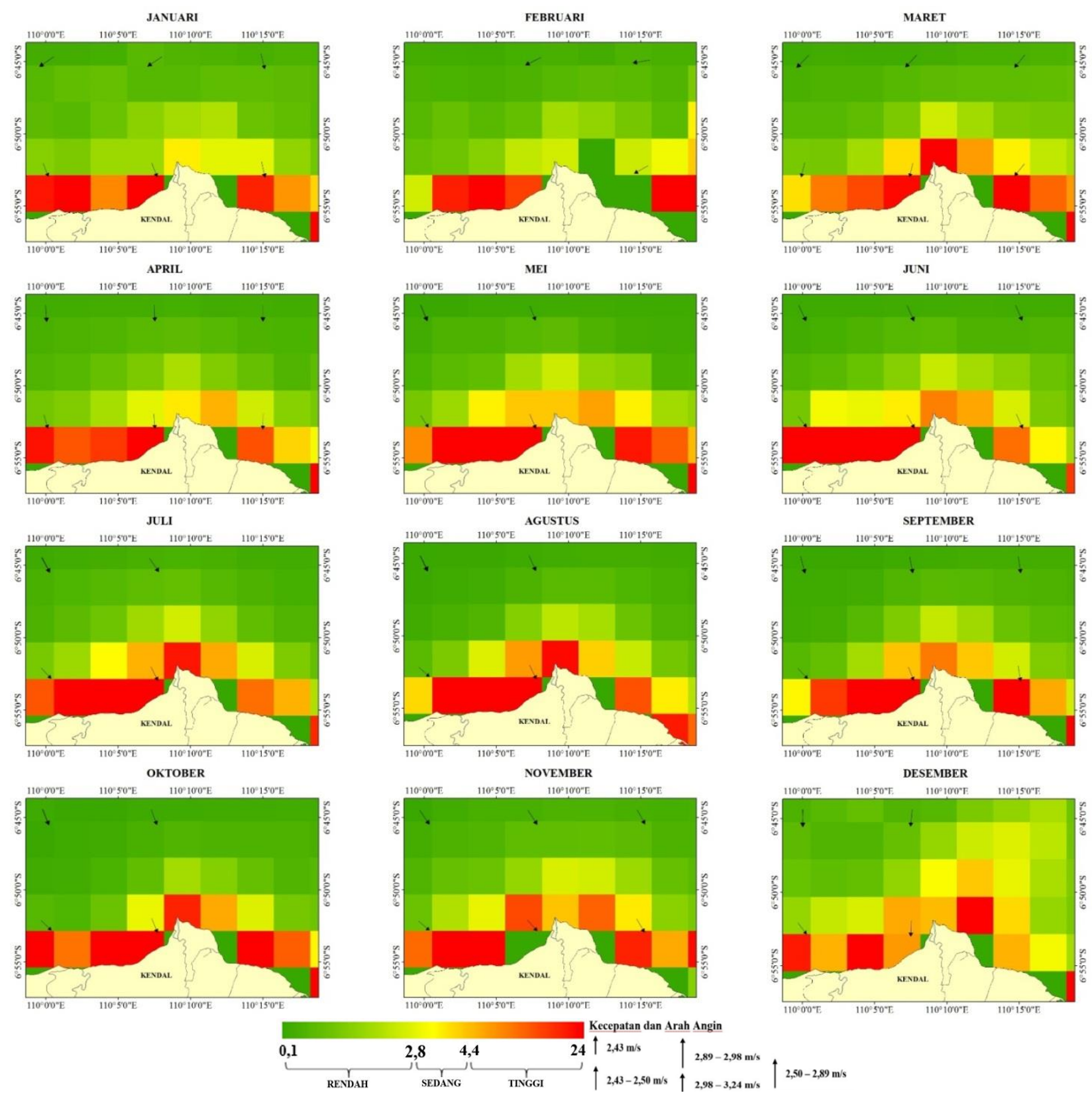
† $2,50-2,89 \mathrm{~m} / \mathrm{s}$

Gambar 8. Hasil Pengolahan Citra Klorofil-a Klimatologi Tumpang Tindih dengan Angin Klimatologi Bulan Januari - Desember. 
Kecepatan angin cenderung berhembus dari Timur Laut menuju Selatan dengan kecepatan angin tertinggi $3,24 \mathrm{~m} / \mathrm{s}$. Persebaran konsentrasi klorofil-a di wilayah pesisir sebagian besar dipengaruhi oleh faktor selain angin, yaitu faktor daratan. Pada perairan Kendal terdapat sungai Bodri dimana lebar sungai tersebut sangat besar sehingga suplai sedimen yang masuk ke muara hingga lepas pantai sangat banyak, sehingga dapat mempengaruhi nilai konsentrasi klorofil-a di perairan tersebut. Pengaruh angin terhadap persebaran klorofil-a di wilayah lepas pantai sangat besar, dibuktikan dengan nilai $R^{2}=$ $=0,616$ bahwa persebaran konsentrasi klorofil-a di wilayah lepas pantai sebagian besar dipengaruhi oleh faktor angin, mekanisme mempengaruhinya yaitu angin yang berhembus di perairan tersebut diduga akan mengakibatkan terjadinya proses mixing sehingga konsentrasi klorofil-a di perairan tersebut sangat bervariasi,

\section{KESIMPULAN}

Nilai sebaran konsentrasi klorofil-a dan suhu permukaan laut di perairan Kendal Jawa Tengah paling tinggi berada di wilayah pesisir. Hubungan korelasi antar dua data klorofil-a dengan tangkapan ikan pelagis kecil dikategorikan sangat erat dengan nilai $R^{2}$ sebesar 0,7685 . Hubungan suhu permukaan laut dengan tangkapan ikan pelagis kecil menunjukkan nilai $R^{2}$ sebesar 0,0028 , dapat disimpulkan suhu permukaan laut tidak berpengaruh besar terhadap hasil tangkapan ikan pelagis kecil. Fishing ground ikan pelagis kecil secara spasial yang dikategorikan berpotensi berada diwilayah pesisir, namun dominan di bagian Barat pesisir Sungai Bodri.

\section{DAFTAR PUSTAKA}

Arikunto, S. 2010. Prosedur Penelitian. Penerbit Rineka Cipta. Jakarta.

Eaton, A.D., Clesceri, L.S., Rice, E.W. \& Greenberg, A.E. 1999. Standard Methods for the Examination of Water and Wastewater. American Public Health Association, American Water Works Association, Water Environment Federation.

Kunarso, Zainuri, M., Ario, R., Munandar, B. \& Prayogi, H. 2018. Impact of Monsoon to Aquatic Productivity and Fish Landing at Pesawaran Regency Waters. IOP Conf. Ser.: Earth Environ. Sci., Vol: 116

Pavlov, D.S \& A. O. Kasumyan. 2000. Patterns and Mechanisms of Schooling Behavior in
Fish: A Review. J. Ichthyol, 40(2):S163S231.

Rahman, R, Triarso, I. \& Asriyanto. 2013. Analisis Bioekonomi Ikan Pelagis Pada Usaha Perikanan Tangkap Di Pelabuhan Perikanan Pantai Tawang Kabupaten Kendal. J. Fish. Res. Utilization Manag. Technol. 2(1):1-10.

Sachoemar, S.I., Yanagi, T., Hendiarti, N., Sadly, M. \& Meliani, F. 2010. Seasonal variability of sea surface cholophyll-a and abundance of pelagic fish in Lampung Bay, southern coastal area of Sumatra, Indonesi, Coast. Mar. Sci., 34(1):82-90.

Sachoemar, S.I., Yanagi, T. \& Aliah, R.S. 2012. Variability of Sea Surface Chlorophyll-A, Temperature and Fish Catch within Indonesian Region Revealed by Satellite Data. Mar. Res. Ind. 37(2):75-87

Setiawan, R.Y. \& Habibi, A. 2011. Satellite Detection of Summer Chlorophyll-a Bloom in the Gulf of Tomini", J. Sel. Topics Appl. Earth Observ. Remote Sens. 4(4):944-948.

Silubun, D.T., Gaol, J.L. \& Naulita, Y. 2015. Estimasi Intensitas Upwelling Pantai Dari Satelit Aqua Modis di Perairan Selatan Jawa dan Barat. J. Teknol Perikanan Kelautan. $6(1)$.

Sugiyono. 2015. Metode Penelitian Kuantitatif, Kualitatif, dan R\&D. Penerbit Alfabeta, Bandung.

Wirasatriya, A., Setiawan, R.Y. \& Subardjo, P. 2017. The effect of ENSO on the variability of chlorophyll-a and sea surface temperature in the Maluku Sea. IEEE JSTARS. 10(12):5513 - 5518. DOI: 10.1109/JSTARS. 2017.2745207

Wirasatriya, A., Prasetyawan, I.B., Triyono, C.D., Muslim \& Maslukah. L., 2018a. Effect of ENSO on The Variability of SST and Chlorophyll-a in Java Sea. IOP Conf. Ser.: Earth Environ. Sci., 116(012063): 1-8. DOI :10.1088/1755-1315/116/1/012 063.

Wirasatriya, A., Kunarso, Maslukah, L., Satriadi, A. \& Armanto., R.D. 2018b. Different responses of chlorophyll-a concentration and Sea Surface Temperature (SST) on southeasterly wind blowing in the Sunda Strait, IOP Conf. Ser.: Earth Environ. Sci. 139: (012028) 